\author{
Military Technical College \\ Kobry El-Kobbah, \\ Cairo, Egypt.
}

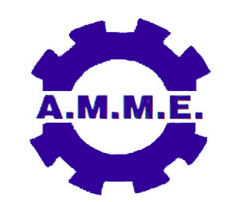

\title{
GRAIN REFINEMENT OF ALUMINUM-BASED NANOCOMPOSITES
}

\author{
H. F. El-Labban*
}

\begin{abstract}
Grain refinement of an aluminum alloy was carried out by adding 0.6 wt.\% Al-Ti5-B1 master alloy to the aluminum alloy melt at $720{ }^{\circ} \mathrm{C}$ for a holding time of 10 minutes. 2 wt. $\% \mathrm{Al}_{2} \mathrm{O}_{3}$ nanoparticles were added to the base melt and mechanically stirred to produce the nanocomposite. The two types of additions were used in case of the combined treatment. A considerable grain refinement of the aluminum alloy was obtained by the addition of Al-Ti5-B1 to its melt. A nanocomposite of fine matrix grains was also produced. A modified nanocomposite of more refined matrix grains and homogeneous microstructure was produced by application of the combined treatment. Both hardness and wear resistance of the aluminum alloy were increased by grain refinement. Greater increases in these properties were obtained in case of nanocomposite. Remarkable improvements in these properties were achieved in the case of grain refined nanocomposite.
\end{abstract}

\section{KEYWORDS}

Aluminum grain refinement; Aluminum matrix nanocomposites; $\mathrm{Al}_{2} \mathrm{O}_{3}$ nanoparticles; Modification of nanocomposites; Wear resistance.

* Associate Professor, Dept. of Production Engineering, Alexandria University, Alexandria, Egypt. 


\section{INTRODUCTION}

In the normal casting conditions, the metals and alloys are usually solidified with a coarse and columnar grain structure [1-3]. The cast structure affects the mechanical properties [4]. Grain refinement plays an important role in improving properties of cast and wrought aluminium alloys [1,5]. The chemical grain refinement can be carried out using Al-Ti5-B1 master alloy. However, the grain refiners based on Al-Ti$B$ suffer from poisoning in the presence of $\mathrm{Zr}$, and some other elements $[1,2,6]$. To solve this problem, Al-Ti-C-based grain refiners can be used $[1,2,6]$. In addition, the performance of metals and alloys can be enhanced by adding suitable reinforcing materials $[7,8]$. The produced materials are metal matrix composites (MMCs). More outstanding properties over MMCs can be achieved by using reinforcement of nanosize. MMCs with reinforcing particles in the range of $10 \mathrm{~nm}-1 \mu \mathrm{m}$ are termed "Metal Matrix Nano-composites" (MMNCs) [7]. It was reported that, MMNCs overcome the shortcoming of MMCs (such as poor ductility, low fracture toughness and low machinability) [7]. The present study aims to investigate the combined effect of grain refinement (which can be produced by adding Al-Ti5-B1 master alloy) and reinforcement (using $\mathrm{Al}_{2} \mathrm{O}_{3}$ nanoparticles) on the microstructure and some properties and behavior (such as microhardness and wear resistance) of the produced nanocomposites.

\section{EXPERIMENTAL WORK}

The experimental work was planned to carray out three treatments: chemical grain refinement, reinforcement and a combined treatment (addition of both grain refiner and reinforcing particles). In all experiments, aluminum alloy of chemical composition listed in Table 1 was used as a matrix (or base) material. The chemical grain refinement was carried out by adding $0.6 \mathrm{wt} \% \mathrm{Al}-\mathrm{Ti} 5-\mathrm{B} 1$ master alloy to the aluminum alloy melt at $720{ }^{\circ} \mathrm{C}$, mechanically stirred and holded at this temperature for 10 minutes after which the treated melt was poured inside a steel mold. The grain refiner was used in the form of chips produced by turning the Al-Ti5-B1 master alloy rod.

The reinforcement treatment was carried out by adding 2 wt. $\% \mathrm{Al}_{2} \mathrm{O}_{3}$ nanoparticles to the aluminum alloy melt and application of mechanical stirring at the same temperature of the grain refinement treatment. The mechanical stirring aids in reducing the agglomeration of nanoparticles. Finally, in the third treatment, the melt of aluminum alloy was subjected to the combined treatment. This treatment was carried out by adding the two additives: (a) 0.6 wt.\% Al-Ti5-B1 master alloy to the matrix (aluminum alloy) melt at $720{ }^{\circ} \mathrm{C}$ for a holding time of 10 minutes and (b) 2 wt. $\% \mathrm{Al}_{2} \mathrm{O}_{3}$ nanoparticles, after which the mixture of melt and the additives were mechanically stirred. The microstructures of different specimens were investigated using optical and scanning electron microscopes. The different phases and constituents were identified with the aid of EDX and XRD analyses. To evaluate the effect of the different treatments on some properties and behavior of the prepared materials, microhardness and wear tests were conducted. Microhardness of the different materials were measured using microhardness tester with load of $200 \mathrm{~g}$. Wear tests were conducted at load of $544.5 \mathrm{~g}$ for sliding distance of $602.88 \mathrm{~m}$ using a pin on disc wear tester. 
Table 1. Chemical analysis of matrix (base) alloy (wt. \%):

\begin{tabular}{|l|l|l|l|l|l|l|l|l|l|l|l|l|}
\hline $\mathrm{Si}$ & $\mathrm{Fe}$ & $\mathrm{Cu}$ & $\mathrm{Mn}$ & $\mathrm{Mg}$ & $\mathrm{Zn}$ & $\mathrm{Ni}$ & $\mathrm{Cr}$ & $\mathrm{Ti}$ & $\mathrm{Pb}$ & $\mathrm{Sn}$ & $\mathrm{V}$ & $\mathrm{Al}$ \\
\hline 1.04 & 0.245 & 0.041 & 0.54 & 0.62 & 0.021 & 0.021 & 0.012 & 0.035 & 0.024 & 0.028 & 0.013 & Bal. \\
\hline
\end{tabular}

\section{RESULTS AND DISCUSSIONS}

\section{Effect of Treatments on Microstructure}

The microstructures of untreated $\mathrm{Al}$ alloy, grain refined alloy (Al alloy $+0.6 \mathrm{wt} . \% \mathrm{Al}-$ Ti5-B1), nanocomposite (Al alloy/2 wt.\% $\mathrm{Al}_{2} \mathrm{O}_{3}$ nanoparticles), and grain refined nanocomposite are shown in Fig. 1 ( $a, b, c$ and $d$ respectively). In case of the untreated alloy; Fig. 1(a); a microstructure of large grains was obtained. Coarse columnar a-Al dendritic grains are clearly revealed in this figure. With the addition of 0.6 wt.\% of Al-Ti5-B1 master alloy, the coarse dendritic structure was transformed into one of fine and equiaxed grains; Fig. 1(b). In this case and as described in many papers, the $\mathrm{TiB}_{2}$ and $\mathrm{TiAl}_{3}$ (which represent main phases of Al-Ti5-B1) act as heterogeneous nucleation sites for the refined phase. These phases were identified by XRD analysis as shown in Fig. 2. The microstructure of the aluminum alloy-based nanocomposite is shown in Fig. 1(c). As shown in this figure, some grains are refined. Grain refinement of aluminum matrix due to the addition of $\mathrm{Al}_{2} \mathrm{O}_{3}$ nanoparticles was also obtained by other investigators [9-11]. In these cases, the $\mathrm{Al}_{2} \mathrm{O}_{3}$ nanoparticles can act as heterogeneous nucleation sites during solidification. To observe and characterize the features of $\mathrm{Al}_{2} \mathrm{O}_{3}$ nanoparticles (size, distribution and agglomeration) and the bonding between them and the matrix, investigations using scanning electron microscope were done. Figures 3 and 4 represent typical SEM images of this composite and EDX analyses for $\mathrm{Al}_{2} \mathrm{O}_{3}$ nanoparticles. As shown in the images, some $\mathrm{Al}_{2} \mathrm{O}_{3}$ particles are uniformly distributed through the matrix alloy. The EDX analyses show that, some particles are found at the grain boundaries; Fig. 3 and other ones are found at the grain centers; Fig. 4. The particles that are near the grain boundaries are pushed by the solidification front, they seem to be also nucleating sites. The nanoparticles show a rounded agglomerated structure of about 200 to $300 \mathrm{~nm}$. The presence of $\mathrm{Al}_{2} \mathrm{O}_{3}$ can be indicated by $\mathrm{O}$ and part of $\mathrm{Al}$ peaks shown in the EDX analyses; Figs. 3 and 4. The detection zone shown in Fig. 4 is bigger than the analaysed $\mathrm{Al}_{2} \mathrm{O}_{3}$ nanoparticles and as a result the peaks include compositional information of Al matrix near particles.

The combined effect of the two additives (Al-Ti5- $\mathrm{B} 1$ and $\mathrm{Al}_{2} \mathrm{O}_{3}$ ) on the microstructure for the produced material is demonstrated in Fig. 1(d). More refined and homogenized microstructure was produced. This can be attributed to the presence of the different heterogeneous nucleating sites $\left(\mathrm{TiB}_{2}, \mathrm{TiAl}_{3}\right.$ and $\left.\mathrm{Al}_{2} \mathrm{O}_{3}\right)$ and hindering of grain growth which can be resulted from the presence of $\mathrm{Al}_{2} \mathrm{O}_{3}$ particles at the grain boundaries. Some $\mathrm{Al}_{2} \mathrm{O}_{3}$ nanoparticles are agglomerated in some zones as shown in Figs $5(\mathrm{a})$ and 6(a). These particles are confirmed by the EDX analyses; Figs 5 (b) and 6 (b). During solidification processing, nano particulates tend to agglomerate. The agglomeration and non-homogeneous distribution of the reinforcement with 
particle debonding were also observed by other investigators [7,12]. The agglomeration and non-homogeneous distribution of the reinforcing nanoparticles reduces the direct contact and bonding between them and the matrix and consequently the improvement in properties (specially strength) is reduced.

An $\alpha$-Al grain solidified on $\mathrm{TiAl}_{3}$ blocky in the case of grain refined aluminum alloybased nanocomposite is shown in Fig. 7(a). The presence of $\mathrm{TiAl}_{3}$ phase is confirmed by EDX analysis; Fig. 7(b). As described in [5], borides nucleate $\alpha$-Al. However the effectiveness in nucleation of borides is lower than that of $\mathrm{TiAl}_{3}[5]$.

In all EDX analyses; Figs. 3-7; a part of the Al peak is resulted from excitation of a portion of the matrix and the other part is resulted from other constituents (such as $\mathrm{TiAl}_{3}$ or $\mathrm{Al}_{2} \mathrm{O}_{3}$ ). In Fig. 4, portions of both $\mathrm{Al}$ and $\mathrm{Si}$ of matrix are indicated. The peaks of other matrix elements are too low to detected and the analyses were concentrated on the nucleation and reinforcing agents $\left(\mathrm{TiB}_{2}, \mathrm{TiAl}_{3}\right.$ and $\left.\mathrm{Al}_{2} \mathrm{O}_{3}\right)$. The different phases were investigated with the aid of XRD and shown in Fig. 2.

\section{Effect of Treatments on Hardness}

Microhardness of the different materials are listed in Fig. 8. An increase in hardness was obtained by refining the grains. In this case, $34 \%$ improvement in hardness was obtained. It is well known that, the reduce in grain size increases the strength and hardness of the material.

By adding the reinforcing particles, a greater increase in hardness $(41.8 \%$ improvement) was obtained. This can be attributed to the combined effect of the refined matrix grains and the hardening due to the reinforcement. As described above, $\mathrm{Al}_{2} \mathrm{O}_{3}$ nanoparticles act as heterogeneous nucleation sites for aluminum which lead to grain refinement. The resulted grain refinement aids in the strenthening of nanocomposite. The grain-refined strengthening effect of $\mathrm{Al}_{2} \mathrm{O}_{3}$ particulates is also reported by others [10,12]. In addition, the uniform distribution of some $\mathrm{Al}_{2} \mathrm{O}_{3}$ particles aids in the hardness improvement. No decohesion between the $\mathrm{Al}_{2} \mathrm{O}_{3}$ particles and the matrix was observed. This indicate that bonding between the reinforcing particles and the matrix (see figures (4-6)) is strong which is an important factor in improving the hardness and strength. Also, The nano size of reinforcing particles plays another important role in the hardness improvement. This is in agreement with the results of other investigators [13,14]. In these cases, and as stated in [15], the high strain energy for the periphery of particles increases the hardness. Moreover, the difference between the coefficient of thermal expansion (CTE) values of matrix and ceramic particles generates thermally induced residual stresses and increases the dislocations density [16]. As a result the hardness and strength are increased. Also, the high hardness of the ceramic particles ( $2200 \mathrm{HV}$ for alumina) aids in hardness improvemen $[17,18]$. The improvement in hardness of aluminum-based nanocomposite due to reinforcing with alumina was also obtained by other investigators $[12,19]$.

A remarkable improvement $(57.3 \%)$ was achieved in case of grain refined nanocomposite. This can be attributed to the combined effect of grain refinement (resulted from the addition of $\mathrm{Al}-\mathrm{Ti5}-\mathrm{B} 1$ and $\mathrm{Al}_{2} \mathrm{O}_{3}$ nanoparticles), microstructure homogenization and reinforcement with $\mathrm{Al}_{2} \mathrm{O}_{3}$ nanoparticles. This result shows that, 
the hardening effect of the reinforcing agent is improved by grain refinement of the matrix phase.

Based on the analyses for the effect of $\mathrm{Al}_{2} \mathrm{O}_{3}$ nanoparticles on the microstructure features and hardness of the produced Al-based nanocomposite, it can be concluded that, these particles can be considered as a grain refiner and reinforcing agent.

\section{Effect of Treatments on Wear Rate}

Specimens of the different materials were prepared and tested at $544.5 \mathrm{~g}$ and sliding distance of $602.88 \mathrm{~m}$. The wear of the different specimens was evaluated by calculating the weight losses per unit area. Figure 9 show the weight losses for the different specimens. $16.7 \%$ reduction in weight losses per unit area was obtained in case of grain refined material. So, the wear rate decreases with the decrease in the grain size. The decrease in grain size increases the hardness and strength. Consequently, the wear rate is decreased. These results are in agreement with those obtained by other investigators [20].

The hardening of material due to the addition of reinforcing particles increases the wear resistance. The reduction in weight losses per unit area in this case is greater than that in the case of grain refinement. In case of the nanocomposite and as described in the treatments and microstructural analyses, very hard nanoparticles $\left(\mathrm{Al}_{2} \mathrm{O}_{3}\right.$ of $\left.\sim 200-300 \mathrm{~nm}\right)$ are uniformly dispersed in the matrix with good interfacial bonding between them and the matrix. In addition, the matrix grains are refined due to the action of these nanoparticles as heterogeneous nucleating sites during solidification of $\alpha$-Al. These microstructural features and the resulted properties (such as high hardness) aid in the wear resistance improvement. These results are in agreement with those obtained by several investigators [7,12,21-28].

A remarkable reduction in the weight losses per unit area was achieved in the case of grain refined nanocomposite. This result can be attributed to the combined effect of grain refinement (resulted due to the addition of conventional grain refiner; Al-Ti5$\mathrm{B} 1$ master alloy; and $\mathrm{Al}_{2} \mathrm{O}_{3}$ nanoparticles) and the reinforcement. In this case, 66.7 $\%$ reduction in weight loss per unit area was obtained.

\section{CONCLUSIONS}

The results of the present study lead to the following conclusions:

1. A considerable grain refinement for the investigated aluminum alloy can be obtained by adding 0.6 wt. $\%$ Al-Ti5-B1 to the melt at $720{ }^{\circ} \mathrm{C}$ for a holding time of 10 minutes.

2. An aluminum matrix nanocomposite of refined matrix grains can be produced by adding 2 wt. $\% \mathrm{Al}_{2} \mathrm{O}_{3}$ nanoparticles to the matrix melt and application of mechanical stirring. Accordingly, the nanoparticles of $\mathrm{Al}_{2} \mathrm{O}_{3}$ can be considered as grain refiner for aluminum alloys.

3. A modified aluminum matrix nanocomposite of more refined matrix grains and homogeneous microstructure can be produced by application of combined treatment (the two treatments: addition of $0.6 \mathrm{wt} . \%$ Al-Ti5-B1 master alloy to the 
matrix (aluminum alloy) melt at $720{ }^{\circ} \mathrm{C}$ for a holding time of 10 minutes and 2 wt. $\% \mathrm{Al}_{2} \mathrm{O}_{3}$ nanoparticles, after which the mixture of melt and the additives are mechanically stirred).

4. Both hardness and wear resistance of the investigated aluminum alloy can be increased by grain refinement.

5. Greater increases in both hardness and wear resistance can be obtained by producing the nanocomposite.

6. Remarkable improvements in both hardness and wear resistance can be achieved by producing the grain refined nanocomposite.

\section{REFERENCES}

[1] I. Naglič, " Influence of Fading and Stirring on the Performance of the AITi5B1 and AITi3C0.15 Grain Refiners in an Al-Fe alloy",Kovove Mater. 48, 191-196, (2010).

[2] I. Naglič, A. Smolej, and M. Doberek, "Remelting of Aluminum with the Addition of AITi5B1 and AITi3C0,15 Grain Refiners", ISSN 0543-5846, METABK 47(2), 115-118, (2008).

[3] I. Naglič, A. Smolej, and M. Doberek, "The Influnce of Alloying Elements in Aluminum on the Grain Refinement with ALTI5B1", ISSN 0543-5846, METABK 48(3), 147-150, (2009).

[4] M. Petrič, J. Med ved and P. Mrvar, "Effect of the Grain Refinement, Modification and the Cooling Rate on Microstructure of the AISi10Mg alloy", RMZ - Materials and Geoenvironment, 53(3), 385-401, (2006).

[5] K. T. Kashyap and T Chandrashekar, " Effects and Mechanisms of Grain Refinement in Aluminium Alloys", Bull. Mater. Sci., 24(4), 345-353, (2001).

[6] I. Naglič, "The Influnce of Stirring on the Fading of the AITi5B1 Grain Refiner in An Al-Fe alloy", ISSN 0543-5846, METABK 50(1), 25-28, (2011).

[7] H. Yu, "Processing Routes for Aluminum based Nano-Composites", M.Sc. in Material Science \& Engineering, WORCESTER POLYTECHNIC INSTITUTE, (2010).

[8] M. Rosso, "Ceramic and Metal Matrix Composites: Route and Properties", 12th International Scientific Conference, Achievements in Mechanical and Materials Engineering, Polish Academy of Science-Committee of Materials Science, AMME'(2003).

[9] A. Mazahery and M. Ostadshabani, "Investigation on Mechanical Properties of Nano- $\mathrm{Al}_{2} \mathrm{O}_{3}$-Reinforced Aluminum Matrix Composites", Journal of Composite Materials 45(24), 2579-2586, (2011).

[10] M. A, Abdizadeh $\mathrm{H}$ and B. HR., "Development of High-Performance A356/Nano- $\mathrm{Al}_{2} \mathrm{O}_{3}$ Composites", Mater Sci Eng A518, 61-64, (2009).

[11] M. Habibnejad-Korayema, R. Mahmudia and WJ.Pooleb, "Enhanced Properties of Mg-based Nano-Composites Reinforced with $\mathrm{Al}_{2} \mathrm{O}_{3}$ NanoParticles", Mater Sci Eng A 519, 198-203, (2009).

[12] C. Borgonovo, "Aluminum Nano-Composites for Elevated Temperature Applications", A Thesis, Faculty of the WORCESTER POLYTECHNIC INSTITUTE, (2010).

[13] J.M. Wu, Z.Z. Li, "Contributions of the Particulate Reinforcement to Dry Sliding Wear Resistance of Rapidly Solidified Al-Ti Alloys", Wear 244, 147153, (2000). 
[14] R.L. Deuis, C. Subramaniun, J.M. Yellup, "Abrasive Wear of Aluminium Composites-A review", Wear 201, 132-144, (1996).

[15] S.W. Kim, U. J. Lee, S. W. Han, D. K. Kim and K. Ogi, "Heat Treatment and Wear Characteristics of Al/SiCp Composites Fabricated by Duplex Process", Composites: Part B 34, 737-745, (2003).

[16] Y.T. Zhao, S.L. Zhang, G. Chen, X.N. Cheng and C.Q. Wang, "In Situ $\left(\mathrm{Al}_{2} \mathrm{O}_{3} \mathrm{Al}_{3} \mathrm{Zr}\right) \mathrm{Np} / \mathrm{Al}$ Nanocomposites Synthesized by Magneto-Chemical Melt Reaction", Compos Sci Technol 68, 1463-1470, (2008).

[17] A. A. Hamid, P.K. Ghosh, S.C. Jain and S. Ray, "The Influence of Porosity and Particles Content on Dry Sliding Wear of Cast in Situ $\mathrm{Al}(\mathrm{Ti})-\mathrm{Al}_{2} \mathrm{O}_{3}\left(\mathrm{TiO}_{2}\right)$ Composite", Wear 265, Issues 1-2, 14-26, (2008).

[18] A. A. Hamid, P.K. Ghosh, S.C. Jain and S. Ray, "Influence of Particle Content and Porosity on the Wear Behaviour of Cast in Situ $\mathrm{Al}(\mathrm{Mn})-$ $\mathrm{Al}_{2} \mathrm{O}_{3}\left(\mathrm{MnO}_{2}\right)$ Composite", Wear 260, 368-378, (2006).

[19] S.A. Sajjadi, H.R. Ezatpour and M. Torabi Parizi, "Comparison of Microstructure and Mechanical Properties of A356 Aluminum Alloy/ $/ \mathrm{Al}_{2} \mathrm{O}_{3}$ Composites Fabricated by Stir and Compo-Casting Processes", Materials and Design 34, 106-111, (2012).

[20] A.K. Prasada Rao, K. Das, B.S. Murty, M. Chakraborty, "Microstructure and the Wear Mechanism of Grain-Refined Aluminum During Dry Sliding Against Steel Disc", Wear 264, Issues 7-8, 638-647, (2008).

[21] H. Ye, "An Overview of the Development of Al-Si-Alloy Based Material for Engine Applications", JMEPEG 12, 288-297, (2003).

[22] S. Das, S. Gupta, D.P. Mondal, B.K. Prasad, "Influence of Load and Abrasive Size on the Two Body Abrasive Wear of Al-SiC Composites", Aluminum Trans. 2, 27-36, (2000).

[23] S. Das, D.P. Mondal, G. Dixit, "Mechanical Properties of Pressure Die Cast Al Hard Part Composite", Metall. Mater. Trans. 33A, 633-642, (2001).

[24] G.Y. Lee, C.K.H. Dharan, R.O. Ritchie, "A Physically Based Abrasive Wear Model for Composite Materials", Wear 252 (3-4), 322-331, (2002).

[25] A.A. Torrance, "The Effect of Grit Size and Asperity Blunting on Abrasive Wear", Wear 253, 813-819, (2002).

[26] F. Tang, X. Wu, S. Gec, J. Ye, H. Zhu, M. Hagiwara, J. M. Schoenung, "Dry Sliding Friction and Wear Properties of $\mathrm{B}_{4} \mathrm{C}$ Particulate-Reinforced Al-5083 Matrix Composites", Wear 264, Issues 7-8, 555-561, (2008).

[27] H. Zhu., H. Wang, L. Ge, "Wear Properties of the Composites Fabricated by Exothermic Dispersion Reaction Synthesis in An Al- $\mathrm{TiO}_{2}-\mathrm{B}_{2} \mathrm{O}_{3}$ System", Wear 264, Issues 11-12, 967-972, (2008).

[28] S. Das, D.P. Mondal, S. Sawla, N. Ramakrishnan, "Synergic Effect of Reinforcement and Heat Treatment on the Two Body Abrasive Wear of An Al-Si Alloy Under Varying Loads and Abrasive Sizes", Wear 264, 47-59, (2008). 


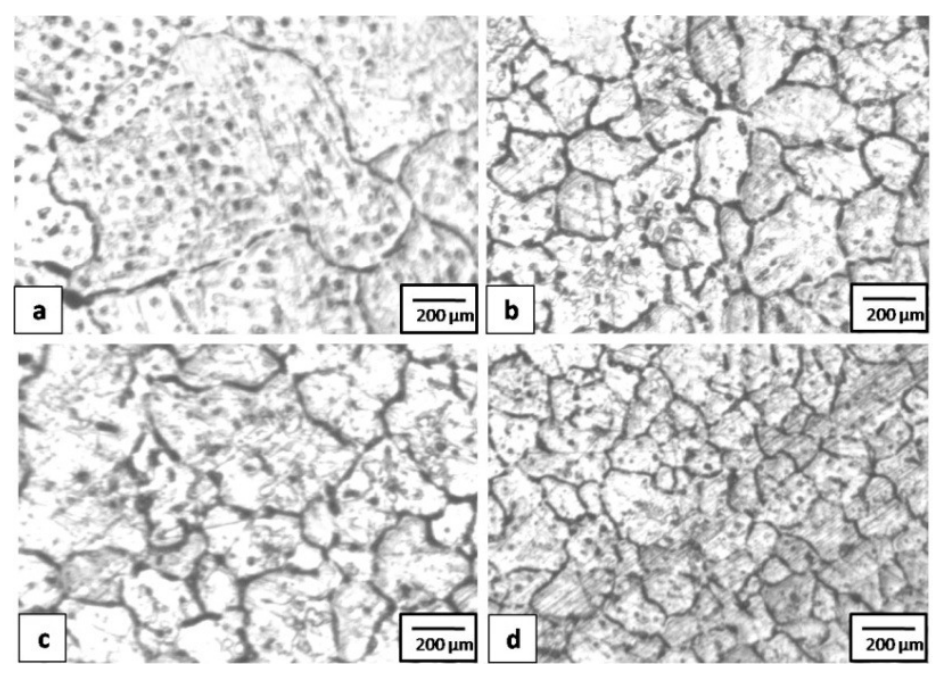

Fig. 1. Optical micrographs for microstructures of untreated and treated material: (a) untreated Al alloy, (b) grain refined alloy (Al alloy + 0.6 wt.\% Al-Ti5-B1), (c) nanocomposite (Al alloy/2 wt. $\% \mathrm{Al}_{2} \mathrm{O}_{3}$ nanoparticles), and (d) Grain refined nanocomposite (Al alloy/2 wt. $\% \mathrm{Al}_{2} \mathrm{O}_{3}$ nanoparticles + 0.6 wt. $\left.\% \mathrm{Al}-\mathrm{Ti5}-\mathrm{B} 1\right)$.

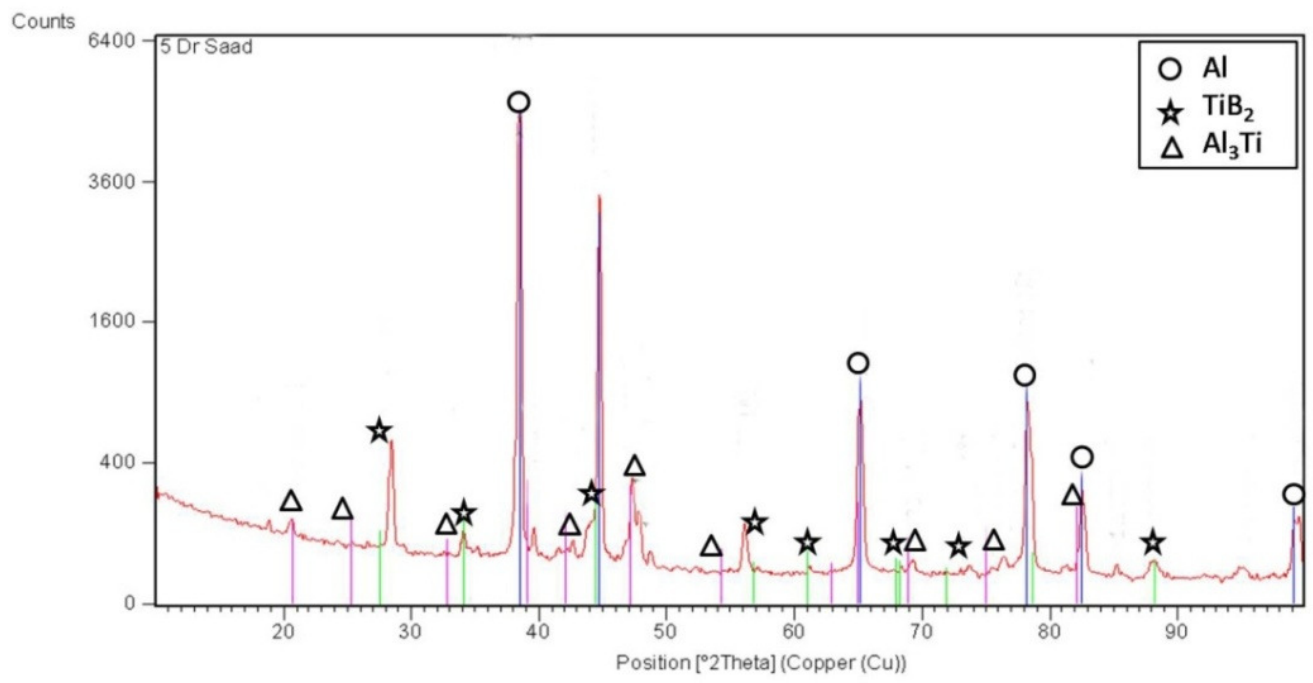

Fig. 2. XRD analysis for constituents and phases of grain refined aluminum alloy. 


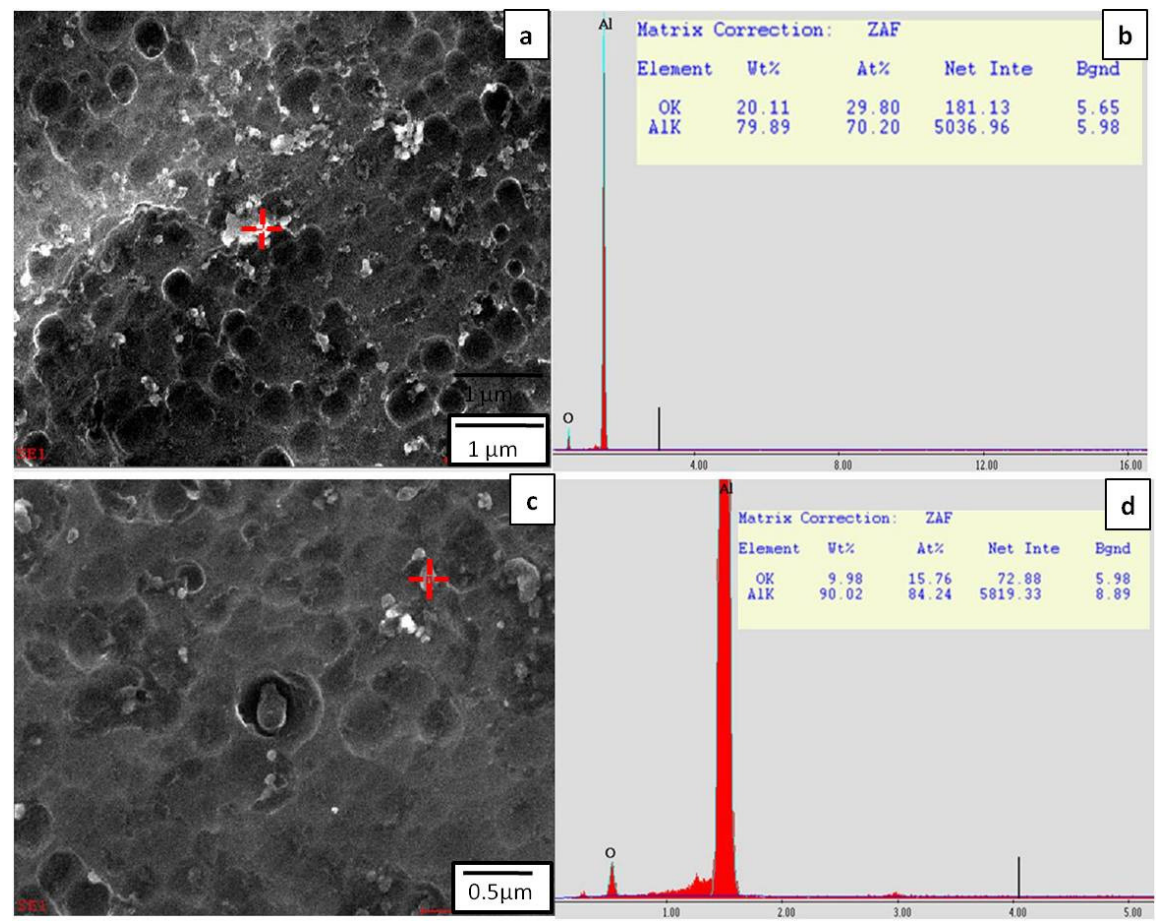

Fig. 3. EDX analysis for elements of $\mathrm{Al}_{2} \mathrm{O}_{3}$ nanoparticles (marked by red cross) at grain boundaries in case of the nanocomposite.

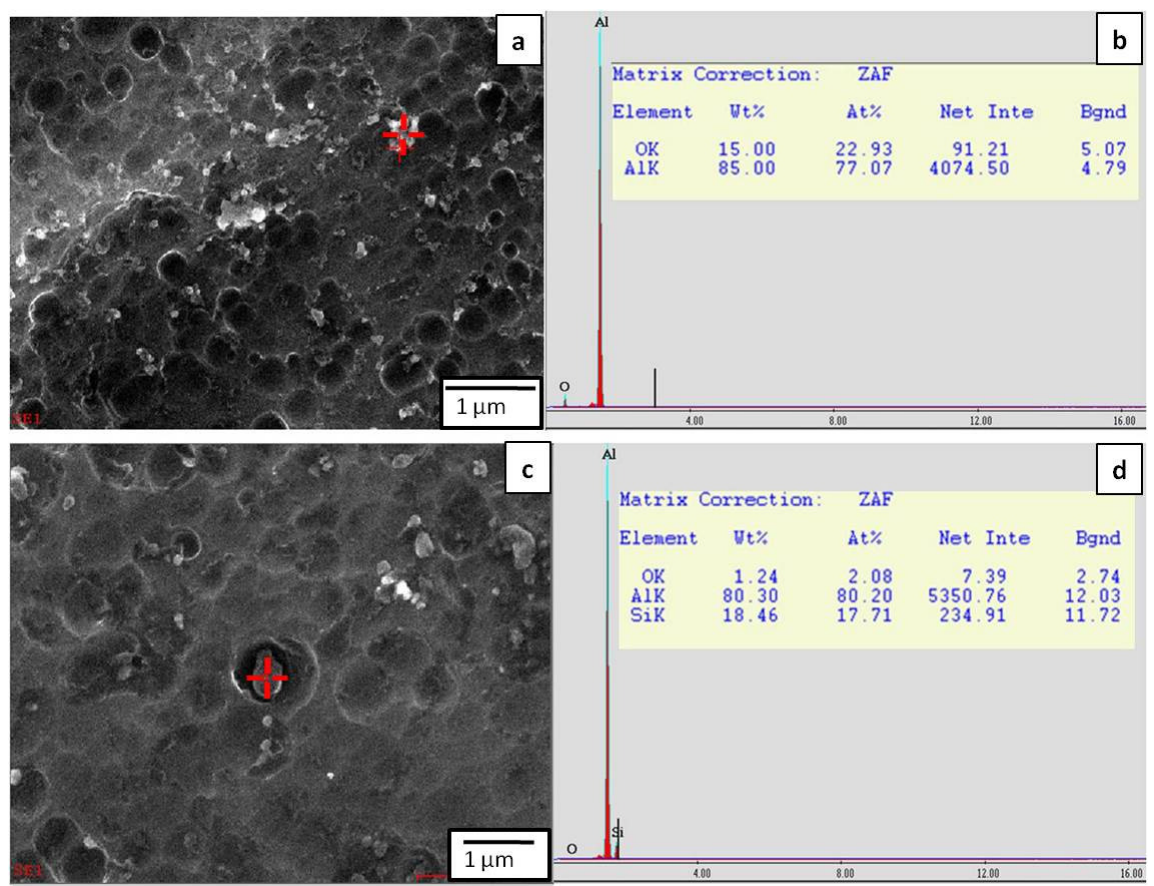

Fig. 4. EDX analysis for elements of $\mathrm{Al}_{2} \mathrm{O}_{3}$ nanoparticles (marked by red cross) on which a grain is solidified in case of the nanocomposite. 

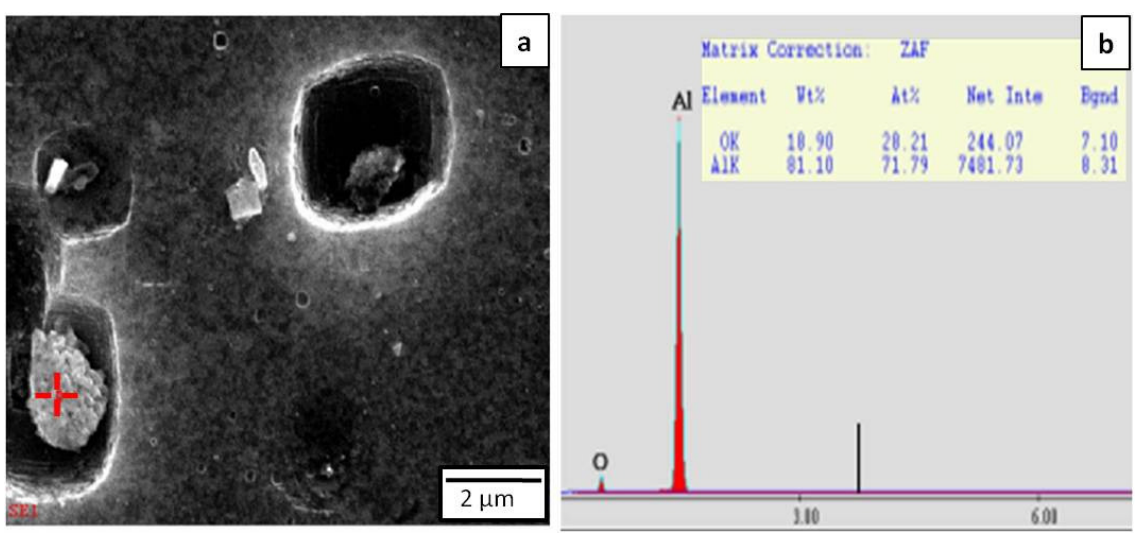

Fig. 5. (a) SEM image for microstructure of grain refined nanocomposite. The figure shows the accumulated $\mathrm{Al}_{2} \mathrm{O}_{3}$ nanoparticles. ( b) EDX analysis for elements of $\mathrm{Al}_{2} \mathrm{O}_{3}$ nanoparticles.

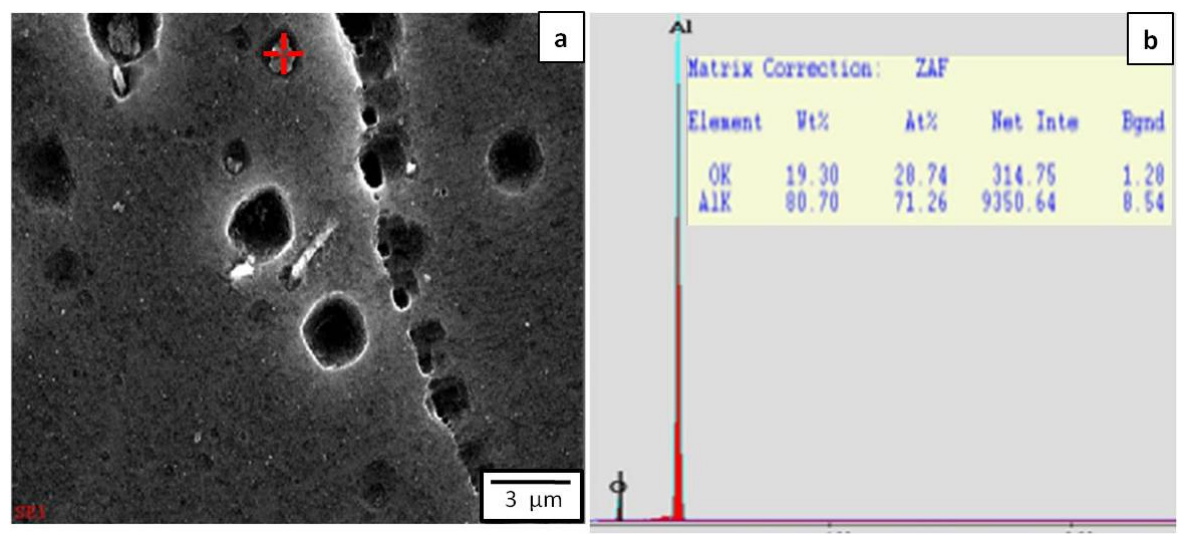

Fig. 6. (a) SEM image for microstructure of grain refined nanocomposite. The figure shows accumulated $\mathrm{Al}_{2} \mathrm{O}_{3}$ nanoparticles inside the grain. (b) EDX analysis for elements of some accumulated $\mathrm{Al}_{2} \mathrm{O}_{3}$ nanoparticles (marked by red cross) in the microstructure.

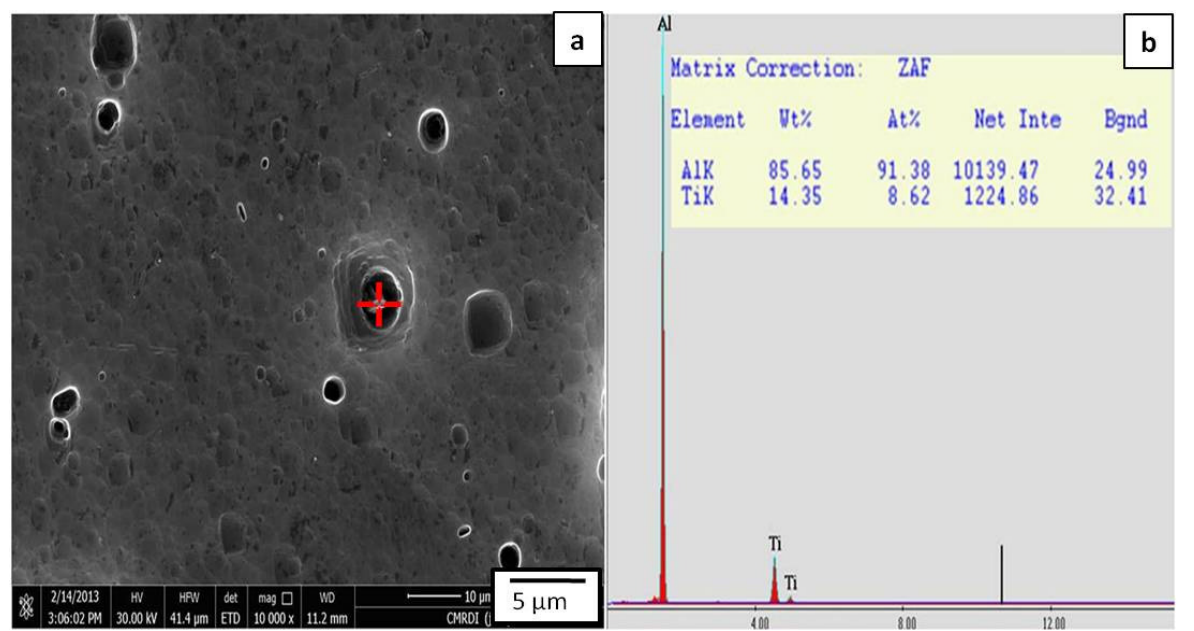

Fig. 7. (a) SEM image for microstructure of grain refined nanocomposite. (b) EDX analysis for elements of $\mathrm{TiAl}_{3}$ on which a matrix grain is solidified. 


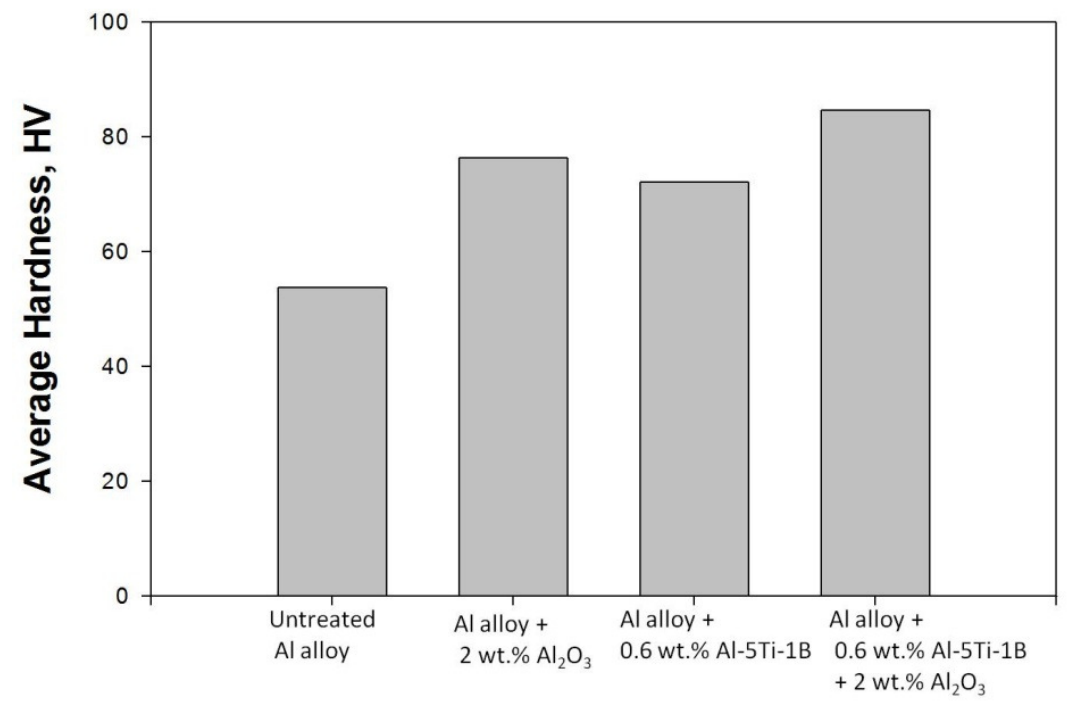

Measured material

Fig. 8. Microhardness of the different materials, $\mathrm{HV}_{0.2}$

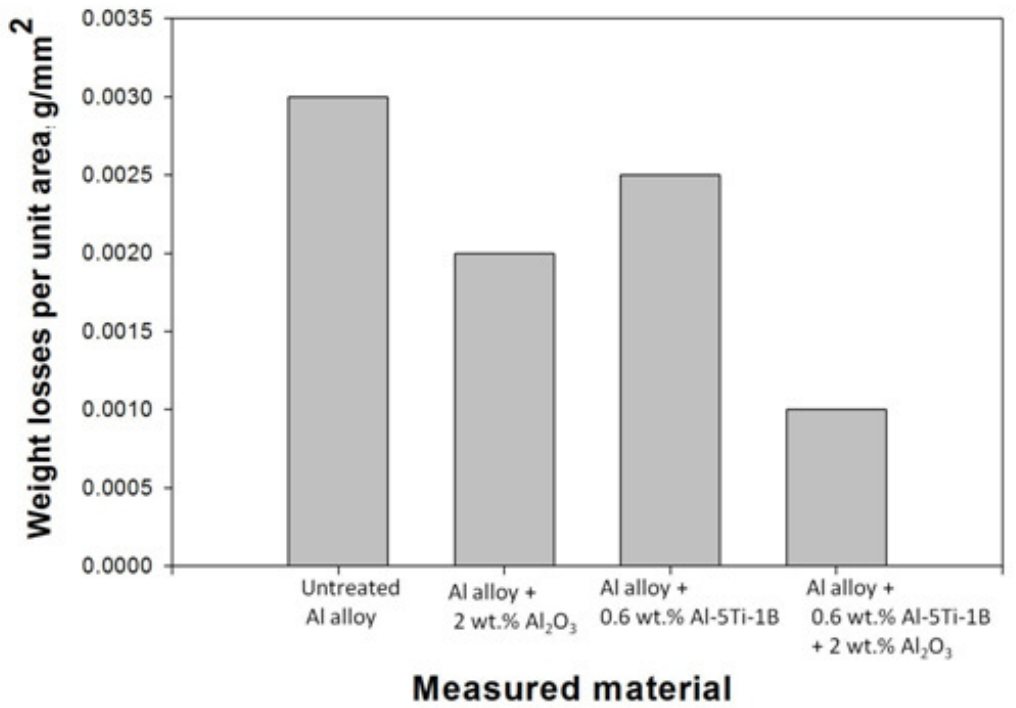

Fig. 9. Weight losses for the different specimens tested at $544.5 \mathrm{~g}$ and sliding distance of $602.88 \mathrm{~m}$. 